\title{
Physicians' beliefs and attitudes about Benzodiazepines: a cross-sectional study
}

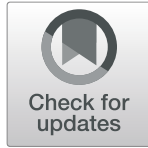

\author{
Inês Teixeira Neves', Joana Sara Silva Oliveira ${ }^{1,2}$, Milene Catarina Coelho Fernandes', \\ Osvaldo Rodrigues Santos ${ }^{1,3}$ and Vasco António Jesus Maria ${ }^{1,2^{*}}$ (D)
}

\begin{abstract}
Background: In 2015, Portugal was the OECD country with the highest reported consumption of BZD. Physician's perceptions and attitudes regarding BZD are main determinants of related prescription habits. This study aimed to characterize beliefs and attitudes of Portuguese physicians regarding the prescription, management challenges, benefits, risks and withdrawal effects of BZD.

Methods: A cross-sectional, observational study with online data collection through anonymous self-administered questionnaire. Physicians registered with the Portuguese Medical Association were invited to participate through direct e-mail message. Physicians were asked to give their opinion (using a 5-points Likert scale) regarding the prescription of BZD, their benefits and risks in the management of insomnia and anxiety, the possible adverse effects of chronic use and alternative non-pharmacologic approaches. Descriptive statistics were used and groups were compared through logistic regression.

Results: A total of 329 physicians participated in the study (56\% family physicians). Mean age was $44.10 \pm 15.2$ years, with $19.03 \pm 14.9$ years of clinical experience. Fifty eight percent of participants were female. Physicians reported BZD's negative impact on cognitive function (89\%), association with road traffic accidents (88\%) and falls (79\%). Also, 58\% shared the belief that chronic use is justified if the patient feels better and without adverse events. Although 68\% reported to feel capable of helping patients to reduce or stop BZD, 55\% recognized difficulties in motivating them. Compared to other medical specialists (altogether), family physicians were significantly more aware about the adverse effects of BZD and considered that chronic use may not be justified. Conversely, more family physicians expressed concerns about their skills to motivate patients engaging in withdrawal programs and to support them during the process.
\end{abstract}

Conclusion: Our results show that physicians' awareness about risks of BZD chronic use is adequate though their attitudes and self-perceived skills towards promoting BZD withdrawal can be improved. Interventions in primary care are needed to capacitate physicians to better motivate patients for BZD withdrawal.

Keywords: Benzodiazepines, Physicians, Beliefs, Attitudes, Survey

\section{Background}

Benzodiazepines (BZD) were introduced in clinical practice as anxiolytic agents in the early 60 s [1]. This class of drugs is used in the treatment of anxiety and sleep disorders, among other conditions for which their effectiveness is well established $[2,3]$. Although BZD are approved for

\footnotetext{
* Correspondence: vascomaria@medicina.ulisboa.pt

'Instituto de Medicina Preventiva e Saúde Pública, Faculdade de Medicina, Universidade de Lisboa, Av. Prof. Egas Moniz, 1649-028 Lisbon, Portugal

${ }^{2}$ Administração Regional de Saúde de Lisboa e Vale do Tejo IP, Av. Estados

Unidos da América 77, 1700-179 Lisbon, Portugal

Full list of author information is available at the end of the article
}

short-term treatment, its long-term use is common and recognized as a relevant public health problem $[4,5]$.

In the United States, a study reported that approximately $5.2 \%$ of adults (18-80 years) used BZD, and that the long-term consumption increased with age, from $14.7 \%$ ( $18-35$ years) to $31.4 \%$ (65-80 years) [6]. Another study in British Columbia showed that between 1996 and 2006, the use of BZD increased from 7.8 to $8.4 \%$, with $3.5 \%$ corresponding to long-term use in 2006 [7]. In Europe, the consumption of BZD is even higher. In Spain, BZD consumption has undergone continued growth since

(c) The Author(s). 2019 Open Access This article is distributed under the terms of the Creative Commons Attribution 4.0 International License (http://creativecommons.org/licenses/by/4.0/), which permits unrestricted use, distribution, and 
2000, from a DHD (Defined Daily Dose per 1000 persons) of 56.7 to a DHD of 89.3 in 2012 [8, 9]. In Portugal, the consumption of BZD was 96 DHD in 2012, 6\% more than in 2000 [10]. Compared with other European countries, Portugal is the OECD country with the highest reported consumption of BZD, with 114 DHD in 2015 versus 87 DHD in Spain and 16 DHD in the United Kingdom [11].

The BZD long-term use has been discouraged due to risks of dependence and negative impact on psychomotor abilities, particularly in older patients, with increased risk of falls and fractures [12] as well as road-traffic accidents [13]. More recently, BZD long-term use has been associated with cognitive deficits and dementia syndromes [14-17]. Hence, it is important to implement prevention programs for inappropriate BZD use and to motivate patients with chronic consumption to participate in supervised programs of BZD discontinuation $[2,18,19]$.

Several studies regarding BZD prescription have shown that the decision to prescribe and maintain the BZD is complex and affected by several factors [20-23], including physicians' knowledge, beliefs and attitudes regarding benefits and risks of BZD [24]. In fact, even though guidelines recommend that non-pharmacological interventions should be used as a first-line treatment for anxiety [25] and sleep disorders [26], the prescription of BZD may be perceived by medical doctors as an easier and more accessible way to address these health conditions [24], particularly in the primary healthcare setting. Indeed, though other medical specialists often decide BZD initiation, family physicians are the main prescribers in the long-term use [27, 28]. The limited consultation time per patient, the patients' pressure for prescription refill and the perceived low risks and high effectiveness of BZD [24, 29] may influence whether or not to initiate, continue or terminate the prescription of BZD.

This study aimed to characterize beliefs and attitudes of Portuguese physicians regarding prescription, consumption and withdrawal of BZD. This is part of a broader project that evaluated the feasibility and effectiveness of a clinical protocol for BZD discontinuation at primary health care level.

\section{Methods}

\section{Study design}

A cross-sectional study was conducted with data collected from December 2015 to February 2016, among physicians registered with the Portuguese Medical Association (PMA). The study was approved by the Regional Health Administrations' Ethics Committee and authorized by the Portuguese Data Protection Authority. Data were collected through Google Forms ${ }^{\circ}$ and compiled into a protected database, only accessible to the research team.

\section{Instrument and procedure}

An anonymous self-administered online questionnaire was developed for this study. The initial version of the questionnaire was developed taking into consideration results of qualitative studies investigating dimensions and factors related with BZD prescribing and usage [20-24, 29]. The questionnaire comprises four different sections: i) general beliefs about BZD, mainly about risks and benefits, ii) attitudes about prescription and chronic use of BZD, iii) self-perception of literacy about BZD and iv) self-efficacy perception for promoting withdrawal.

The questionnaire's validation procedure consisted in discussions between the research team and two external experts on the relevance of the selected dimensions and factors (content validity). Additionally, six physicians of different specialties were invited to respond to the questionnaire to test general comprehension and consistency.

The final version of the questionnaire was named Perception about Use of BZD Scale (PUBS) and included 30 items (see Table 3). Respondents expressed their agreement with each of the statements through a 5-point Likert scale that ranged from "1-Strongly disagree" to "5-Strongly agree". Physicians from all Specialist Colleges were invited to participate through direct e-mail, sent by the PMA. The email message included a brief information about the study and a link that landed in a webpage with more information about the participation procedure and goals. Physicians had access to the questionnaire after agreeing with the participation terms (by clicking on a "I agree" box). A reminder was sent by e-mail 1 month after the first message. Because answers were anonymous, the reminder was sent to the complete list of physicians, and it was requested to those that had participated in the first round to skip the invitation.

\section{Statistical analysis}

Data were exported to and analyzed with $\mathrm{IBM}^{\circ} \mathrm{SPSS}^{\circ}$ (version 22.0). Exploratory factor analysis was performed to study the structure of the questionnaire. The principal components extraction method with Varimax rotation was used. Each item was allocated to a factor when having a loading of 0.4 or higher. Sampling adequacy was tested with Kaiser-Meyer-Olkin (KMO) measure and sphericity was tested with Bartlett's test. Cronbach's alpha was used to assess the internal reliability of the complete set of items as well as for each dimension that emerged from the factor analysis.

The preliminary psychometric properties' analysis fully supported the PUBS initial structure of four dimensions [30]. 1) Doctors' beliefs about BZD (items: 1, 2, 3, 4, 5, 6, 7, 8, 9, 10 e 11; alpha coefficient $=0.84)$; 2) Doctors' attitudes about BZD prescription (items: 13, 14, 15, 16, 17, 18, 19, 22, 23, 24, 26, 27, 30; alpha coefficient = 0.65); 3) Doctors' self-perception of literacy about BZD (items: 12, 21, 25; 
alpha coefficient $=0.60)$; 4) Doctors' self-efficacy perception for promoting withdrawal (items: 20, 28, 29; alpha coefficient $=0.41$ ). The overall alpha coefficient of PUBS was 0.78 .

The sample was compared with the population of physicians registered with the PMA regarding main sociodemographic variables and distribution by medical specialties. The data regarding the number of physicians registered with PMA was obtained through the official PMA website (www.ordemdosmedicos.pt).

Univariate descriptive analysis was conducted to describe PUBS items. Total score of the scale, as well as scores for each dimension, were computed as a linear sum. Logistic regression test was used for studying the association between type of medical specialty (family physicians versus other medical specialists, due to the small sample size of these other specialties) and agreement with each item. Comparisons of PUBS mean scores by type of medical specialty were done through Student's $t$ test for independent samples.

\section{Results}

A total of 329 physicians, including 56\% family physicians, participated in the study. The mean age was 44.1 \pm 15.2 years, with $19.0 \pm 14.9$ years of clinical experience. Fifty eight percent of participants were female (Table 1). Regarding their clinical practice, 36\% of the respondents worked mainly at a hospital. Regarding the category "other medical specialists", $6 \%$ of respondents were psychiatrists with $20.4 \pm 15.2$ years of clinical experience and $5 \%$ were internists, with $17.4 \pm 14.4$ years of clinical experience.

Table 2 presents the answers to the PUBS questionnaire. Regarding beliefs about BZD, 30\% of physicians considered that patients get a high-quality sleep with BZD, with significant differences between family physicians and other specialists. Most respondents were aware of BZD negative impact on cognitive function (89\%) and about BZD association with road traffic accidents (88\%) and falls (79\%). Compared to other physicians, family physicians were significantly more aware of BZD impact on cognitive function $(\mathrm{OR}=4.75)$, of $B Z D$ association with falls $(\mathrm{OR}=5.48)$ and of increased risk of road traffic accidents $(\mathrm{OR}=2.49)$.

When considering attitudes towards BZD prescription, $42 \%$ of respondents disagreed with the statement that chronic use is justified if the patient feels better with no observed side effects. Although $68 \%$ felt capable of helping patients to reduce/stop benzodiazepines, 55\% recognized difficulties in motivating them. Half of the physicians (51\%) agreed that they feel pressured by patients to prescribe BZD. Compared to other physicians, family physicians have higher odds in believing that patients feel they are not being taken seriously if the BZD are not prescribed, and that they might be compromising the patient-doctor relationship when not fulfilling such expectation.

Regarding the four dimensions of the PUBS, significant differences were found between family physicians and other medical specialists (Table 3). Family physicians had less positive beliefs regarding BZD and less positive

Table 1 Characteristics of the respondents

\begin{tabular}{|c|c|c|c|c|}
\hline & Family physicians ( $n=184$ ) & $\begin{array}{l}\text { Other medical specialists } \\
(n=145)\end{array}$ & $p$-value & $\begin{array}{l}\text { Total } \\
(n=329)\end{array}$ \\
\hline \multicolumn{5}{|l|}{ Gender, n (\%) } \\
\hline Female & $116(63.0 \%)$ & $74(51.0 \%)$ & $0.03^{a)}$ & $152(57.7 \%)$ \\
\hline Male & $68(37.0 \%)$ & $71(49.0 \%)$ & & $207(42.3 \%)$ \\
\hline \multicolumn{5}{|l|}{ Age group, $n(\%)^{*}$} \\
\hline$\leq 35$ years & 101 (55.2\%) & $50(34.5 \%)$ & $<0.001^{a)}$ & $159(44.4 \%)$ \\
\hline $36-55$ years & $27(14.8 \%)$ & $43(29.7 \%)$ & & $81(22.6 \%)$ \\
\hline$\geq 56$ years & $55(30.1 \%)$ & $52(35.9 \%)$ & & $118(33.0 \%)$ \\
\hline Age, mean $\pm s d^{*}$ & $41.5 \pm 14.3$ & $46.7 \pm 15.9$ & $0.002^{b)}$ & $44.1 \pm 15.2$ \\
\hline Years of clinical practice, mean \pm sd & $16.2 \pm 14.1$ & $22.0 \pm 15.5$ & $<0.001^{\mathrm{b})}$ & $19.0 \pm 15.0$ \\
\hline \multicolumn{5}{|c|}{ Nr of patient with prescribed BZD for the first time (last 3 months) } \\
\hline No patients & $31(16.8 \%)$ & $41(28.3 \%)$ & $<0.001^{\mathrm{a})}$ & $76(21.2 \%)$ \\
\hline Between 1 and 5 patients & $121(65.8 \%)$ & $55(37.9 \%)$ & & $192(53.5 \%)$ \\
\hline Between 6 and 10 patients & $20(10.9 \%)$ & $17(11.7 \%)$ & & $39(10.9 \%)$ \\
\hline More than 10 patients & $5(2.7 \%)$ & $16(11.0 \%)$ & & $25(7.0 \%)$ \\
\hline Not applicable & $7(3.8 \%)$ & $16(11.0 \%)$ & & $27(7.5 \%)$ \\
\hline
\end{tabular}

a) Chi-square test for independence

b) Student's $t$ test for independent samples

*One missing value for variable Age $(n=183)$ 
Table 2 Responses to PUBS item: comparison between family physicians and other specialists

\begin{tabular}{|c|c|c|c|c|c|}
\hline \multirow{2}{*}{$\begin{array}{l}\text { Items } \\
\text { n (\%) }\end{array}$} & \multicolumn{2}{|c|}{ Family physicians $(n=184)$} & \multicolumn{2}{|c|}{ Other specialists $(n=145)$} & \multirow{2}{*}{$\begin{array}{l}\text { OR for agreement } \\
\left(95 \%(\mathrm{Cl})^{c}\right.\end{array}$} \\
\hline & Agreement ${ }^{a}$ & Disagreement $^{b}$ & Agreement $^{a}$ & Disagreement $^{b}$ & \\
\hline \multicolumn{6}{|l|}{ Doctors' beliefs about BZD } \\
\hline 1. With BZD, the patient gets a high-quality sleep & $44(23.9 \%)$ & $94(51.1 \%)$ & $55(37.9 \%)$ & $57(39.3 \%)$ & $1.94^{* *}(1.21-3.13)$ \\
\hline $\begin{array}{l}\text { 2. With BZD, the patient does not wake up so many } \\
\text { times during night }\end{array}$ & $115(62.5 \%)$ & $28(15.2 \%)$ & $93(64.1 \%)$ & $33(22.8 \%)$ & $1.07(0.68-1.69)$ \\
\hline $\begin{array}{l}\text { 3. With } B Z D \text {, the patient feels more rested when } \\
\text { waking up in the morning }\end{array}$ & $50(27.2 \%)$ & $73(39.7 \%)$ & $39(26.9 \%)$ & $54(37.2 \%)$ & $0.99(0.60-1.61)$ \\
\hline 4. With BZD, the patient feels less angry & 99 (53.8\%) & $32(17.4 \%)$ & $96(66.2 \%)$ & $23(15.9 \%)$ & $1.68 *(1.07-2.64)$ \\
\hline $\begin{array}{l}\text { 5. Chronic use of BZD does not represent a health risk } \\
\text { to the patient }\end{array}$ & $7(3.8 \%)$ & $170(92.4 \%)$ & $11(7.6 \%)$ & $119(82.1 \%)$ & $2.08(0.78-5.49)$ \\
\hline 6. Chronic use of BZD contributes to the patients' well-being & $41(22.3 \%)$ & $81(44 \%)$ & $48(33.1 \%)$ & $48(33.1 \%)$ & $1.73^{*}(1.06-2.82)$ \\
\hline 7. Chronic use of BZD is essential to patients' anxiety control & $51(27.7 \%)$ & $85(46.2 \%)$ & $48(33.1 \%)$ & $67(46.2 \%)$ & $1.29(0.80-2.07)$ \\
\hline 8. Chronic use of BZD is a public health problem & $157(85.3 \%)$ & $12(6.5 \%)$ & $113(77.9 \%)$ & $14(9.7 \%)$ & $1.62(0.72-3.64)$ \\
\hline 9. Chronic use of BZD enhances the risk of several falls & $161(87.5 \%)$ & $6(3.3 \%)$ & $98(67.6 \%)$ & $20(13.8 \%)$ & $5.48^{* *}(2.13-14.10)$ \\
\hline 10. Chronic use of BZD may impair cognitive performance & $174(94.6 \%)$ & $4(2.2 \%)$ & $119(82.1 \%)$ & $13(9 \%)$ & $4.75^{* *}(1.51-14.92)$ \\
\hline $\begin{array}{l}\text { 11. Chronic use of BZD increases the risk of road } \\
\text { traffic accidents }\end{array}$ & $168(91.3 \%)$ & $5(2.7 \%)$ & $121(83.4 \%)$ & $9(6.2 \%)$ & $2.49^{*}(0.82-7.64)$ \\
\hline \multicolumn{6}{|l|}{ Doctors' attitudes about BZD prescription } \\
\hline 13. BZD consumption in unnecessary in most cases & $121(65.8 \%)$ & $24(13 \%)$ & $83(57.2 \%)$ & $25(17.2 \%)$ & $1.52(0.81-2.84)$ \\
\hline $\begin{array}{l}\text { 14. It is important to inform the patient about the risk of } \\
\text { tolerance associated with BZD }\end{array}$ & $181(98.4 \%)$ & $1(0.5 \%)$ & $138(95.2 \%)$ & $1(0.7 \%)$ & $1.31(0.08-21.16)$ \\
\hline $\begin{array}{l}\text { 15. It is important to inform the patient about the risk of } \\
\text { addiction associated with BZD }\end{array}$ & $183(99.5 \%)$ & - & $138(95.2 \%)$ & $4(2.8 \%)$ & $0.10(0.01-0.89)$ \\
\hline $\begin{array}{l}\text { 16. Chronic use of BZD is justified if the patient feels } \\
\text { better and without side effects }\end{array}$ & $47(25.5 \%)$ & $94(51.1 \%)$ & $71(49.0 \%)$ & $44(30.3 \%)$ & $2.79^{* *}(1.76-4.45)$ \\
\hline 17. I feel pressured by patients to prescribe BZD & $125(67.9 \%)$ & $33(17.9 \%)$ & $44(30.3 \%)$ & $74(51 \%)$ & $6.37^{* *}(3.73-10.88)$ \\
\hline $\begin{array}{l}\text { 18. Patients feel like they are not taken seriously } \\
\text { when I don't prescribe BZD }\end{array}$ & $49(26.6 \%)$ & $83(45.1 \%)$ & $20(13.8 \%)$ & $90(62.1 \%)$ & $2.66^{* *}(1.46-4.84)$ \\
\hline $\begin{array}{l}\text { 19. When I refuse to prescribe BZD, I'm challenging } \\
\text { the patient-doctor relationship }\end{array}$ & $37(20.1 \%)$ & $98(53.3 \%)$ & $7(4.8 \%)$ & $109(75.2 \%)$ & $5.88^{* *}(2.51-13.79)$ \\
\hline $\begin{array}{l}\text { 22. There is an acceptable level of anxiety and the } \\
\text { doctor should help people to deal with it }\end{array}$ & $173(94.0 \%)$ & $3(1.6 \%)$ & $140(96.6 \%)$ & $2(1.4 \%)$ & $0.82(0.14-4.99)$ \\
\hline $\begin{array}{l}\text { 23. The easiest way to deal with a patients' anxiety } \\
\text { is to prescribe a BZD }\end{array}$ & $44(23.9 \%)$ & $123(66.8 \%)$ & $28(19.3 \%)$ & $106(73.1 \%)$ & $0.76(0.45-1.29)$ \\
\hline $\begin{array}{l}\text { 24. Prescribing BZD in clinical cases of anxiety is the } \\
\text { most appropriate way to deal with those cases }\end{array}$ & $14(7.6 \%)$ & $119(64.7 \%)$ & $16(11.0 \%)$ & $91(62.8 \%)$ & $1.51(0.71-3.19)$ \\
\hline $\begin{array}{l}\text { 26. Non-pharmacological approaches for anxiety } \\
\text { need to be complemented with medication }\end{array}$ & $39(21.2 \%)$ & $63(34.2 \%)$ & $32(22.1 \%)$ & $52(35.9 \%)$ & $1.05(0.62-1.79)$ \\
\hline $\begin{array}{l}\text { 27. Non-pharmacological approaches for sleep disorders } \\
\text { need to be complemented with medication }\end{array}$ & $39(21.2 \%)$ & $80(43.5 \%)$ & 39 (26.9\%) & $49(33.8 \%)$ & $1.37(0.82-2.28)$ \\
\hline $\begin{array}{l}\text { 30. Non-pharmacological approaches are appropriate } \\
\text { for most patients }\end{array}$ & $94(51.1 \%)$ & $45(24.5 \%)$ & $59(40.7 \%)$ & $37(25.5 \%)$ & $1.31(0.76-2.26)$ \\
\hline \multicolumn{6}{|l|}{ Doctors' self-perception of literacy about BZD } \\
\hline $\begin{array}{l}\text { 12. I consider myself well informed about the benefits } \\
\text { and risks of BZD }\end{array}$ & $161(87.5 \%)$ & $5(2.7 \%)$ & $94(64.8 \%)$ & $21(14.5 \%)$ & $0.26^{* *}(0.15-0.46)$ \\
\hline $\begin{array}{l}\text { 21. I don't feel capable of helping patients to stop/ } \\
\text { reduce the BZD consumption }\end{array}$ & 19 (10.3\%) & $136(73.9 \%)$ & $21(14.5 \%)$ & $90(62.1 \%)$ & $0.60(0.31-1.18)$ \\
\hline $\begin{array}{l}\text { 25. My knowledge on non-pharmacological } \\
\text { approaches is enough to help patient not }\end{array}$ & $68(37.0 \%)$ & $64(34.8 \%)$ & $46(31.7 \%)$ & $61(42.1 \%)$ & $0.79(0.50-1.27)$ \\
\hline
\end{tabular}
to choose for BZD 
Table 2 Responses to PUBS item: comparison between family physicians and other specialists (Continued)

\begin{tabular}{|c|c|c|c|c|c|}
\hline \multirow{2}{*}{$\begin{array}{l}\text { Items } \\
\text { n (\%) }\end{array}$} & \multicolumn{2}{|c|}{ Family physicians $(n=184)$} & \multicolumn{2}{|c|}{ Other specialists ( $n=145)$} & \multirow{2}{*}{$\begin{array}{l}\text { OR for agreement } \\
\left(95 \%(I)^{c}\right.\end{array}$} \\
\hline & Agreement $^{a}$ & Disagreement $^{b}$ & Agreement $^{a}$ & Disagreement ${ }^{b}$ & \\
\hline \multicolumn{6}{|l|}{ Doctors' self-efficacy perception for promoting withdrawal } \\
\hline $\begin{array}{l}\text { 20. I have difficulties in motivating patients to stop } \\
\text { BZDs' consumption }\end{array}$ & $114(62.0 \%)$ & $48(26.1 \%)$ & $66(45.5 \%)$ & $40(27.6 \%)$ & $1.44^{* *}(0.86-2.42)$ \\
\hline 28. Psychological treatment of anxiety is of difficult access & $147(79.9 \%)$ & $27(14.7 \%)$ & $104(71.7 \%)$ & $22(15.2 \%)$ & $0.64(0.38-1.06)$ \\
\hline 29. It is difficult to motivate patients to see a psychologist & $119(64.7 \%)$ & $38(20.7 \%)$ & $81(55.9 \%)$ & $36(24.8 \%)$ & $0.69(0.44-1.08)$ \\
\hline
\end{tabular}

* Statistically significant ( $\mathrm{p}$-value $<.05) ;{ }^{* *}$ Highly statistically significant $(p$-value $<.01)$

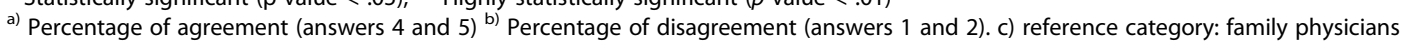

Neutral point (answer 3 - neither agree or disagree) is not included in the table but was considered for the OR estimation

attitudes towards BZD prescribing $(p<0.001)$. On the other hand, family physicians' self-perception of literacy about BZD was significantly higher $(p=0.004)$, except when compared with psychiatrists $(M=3.58$ versus $M=4.10)$.

\section{Discussion}

This study aimed to characterize beliefs and attitudes of the Portuguese physicians regarding BZD prescription, consumption and withdrawal. A self-administered online scale was specifically developed for this purpose, the PUBS, with good psychometric properties when applied to medical doctors from different specialties (alpha coefficient of 0.78). The coefficient for some of the components of the scale (namely the one about Doctors' perception of self-efficacy for promoting withdrawal) are rather low, which is expected due to the low number of items [31]. In any case, the items included in each dimension make sense from a conceptual point of view.

We observed that most physicians were aware of BZD negative impact on cognitive function and their association with falls and fractures and with road-traffic accidents. The scarcity of recent studies investigating physicians' beliefs and attitudes towards BZD prescription makes difficult the external validation of our results [32]. Some older studies appear to show less negative attitudes regarding BZD prescription [21,33]. Risk awareness was higher among family physicians for each of these types of adverse effects, as compared with other specialists ( $\mathrm{OR}=4.75,5.48$ and 2.49 respectively). Family physicians' self-perception of literacy regarding BZD was also significantly higher when compared to other medical specialists $(p=0.004)$. Family physicians considered themselves well informed about benefits and risks of BZD (88\%). However, regarding selfefficacy for promoting withdrawal, there were still $26 \%$ that didn't feel capable to motivate patients to stop or reduce $B Z D$ consumption. Hence, being aware of the risks of BZD chronic use seems to be not enough to capacitate physicians in motivating patients to cease consumption. In fact, a systematic review published in 2013, that included studies conducted in Europe, United Sates, Australia and New Zealand, revealed that family physicians report challenges in helping patients to withdraw from BZD [29]. Since family physicians are usually responsible for prescription refills, the awareness about BZD risks shown in our study may promote and facilitate interventions aimed at reducing its inappropriate and chronic use.

Some studies have reported that physicians may feel ambivalent about the decision to prescribe and maintain the BZD consumption $[21,23,29]$. Concepts such as i) the role of health professionals in BZD prescription; ii) their perception about patients' expectations in receiving a prescription during the appointment; iii) the desire to maintain good doctor-patient relationship; iv) and the difficulty in motivating the patient to accept non-pharmacological

Table 3 PUBS scores by medical specialty

\begin{tabular}{|c|c|c|c|c|c|}
\hline & & Family physicians & Other medical specialists & Total & $p$-value $e^{a}$ \\
\hline \multirow[t]{2}{*}{ Doctors' beliefs about BZD } & Mean (1 to 5 Likert scale) & 2.35 & 2.61 & 2.47 & \multirow[t]{2}{*}{$<0.001^{*}$} \\
\hline & Std. deviation & 0.04 & 0.05 & 0.56 & \\
\hline \multirow[t]{2}{*}{ Doctors' attitudes about BZD prescription } & Mean (1 to 5 Likert scale) & 2.40 & 2.66 & 2.52 & \multirow[t]{2}{*}{$<0.001^{*}$} \\
\hline & Std. deviation & 0.03 & 0.03 & 0.38 & \\
\hline \multirow[t]{2}{*}{ Doctors' self-perception of literacy about BZD } & Mean (1 to 5 Likert scale) & 3.58 & 3.37 & 3.47 & \multirow[t]{2}{*}{$0.004^{*}$} \\
\hline & Std. deviation & 0.04 & 0.06 & 0.67 & \\
\hline \multirow{2}{*}{$\begin{array}{l}\text { Doctors' perception of self-efficacy for } \\
\text { promoting withdrawal }\end{array}$} & Mean (1 to 5 Likert scale) & 3.35 & 3.30 & 3.33 & \multirow[t]{2}{*}{0.440} \\
\hline & Std. deviation & 0.04 & 0.05 & 0.57 & \\
\hline
\end{tabular}

* Statistically significant ( $p$-value $<0.05)$

a) Student's $t$ test for independent samples (comparisons of mean PUBS scores by type of medical speciality) 
interventions, all these are central in BZD inappropriate prescribing decision $[24,27,29,34]$. Our results are also consistent with these concepts, since we observed that family physicians have higher odds in believing that patients feel they are not being taken seriously when the physician refuses a BZD prescription refill, and that this might compromise the doctor-patient relationship. Also, half of the physicians (51\%) reported that they feel pressured by patients to prescribe BZD and 55\% recognized difficulties in motivation them to withdraw BZD. The long-term use of these drugs may also be influenced by other aspects such as: i) patients' lack of knowledge about the risks and benefits of BZD [21]; ii) patients' social or financial problems; iii) the medicalization phenomenon of human suffering and iv) shortage of timely available services of psychological counselling and brief psychotherapeutic interventions $[27,35,36]$. Furthermore, several studies support the hypothesis that BZD proper use depends on the information provided to patients by the prescriber [22, 24, 29].

Difficulties felt by family physicians could be explained by lack of training on how to manage beliefs, motivations and expectations of BZD chronic users, as well as lack of training for managing the BZD discontinuation from a pharmacological perspective. Though recommendations exist on the cautious prescription and utilization of BZD in the treatment of anxiety and insomnia, there are no formal guidelines in Portugal on how to proceed to help patients cease or reduce BZD consumption.

Therefore, we believe that there is a need to develop and validate a clinical protocol to support physicians and patients in the process of BZD withdrawal at Primary Care level. In addition, family physicians should receive adequate training in motivational competencies, in order to facilitate the patients' adherence to the discontinuation program. Integrating motivational interview principles [37] with discontinuation programs may be a strategic and effective way-to-go, for handling resistant or ambivalent patients regarding BZD's withdrawal [38].

Regarding factors influencing initiation and maintenance of BZD chronic use, $68 \%$ of family physicians considered themselves to be pressured by patients to prescribe BZD. This result is consistent with a study conducted by Anthierens and colleagues [21] in which family physicians reported that they were cautious in initiating BZD usage, but at the same time, felt overwhelmed by the psychosocial problems of their patients. This difficulty in dealing with patient's complaints of anxiety and insomnia and the few available non-pharmacological alternatives at a short-term period, can easily lead to BZD over-prescription.

Some study limitations should be acknowledged. A total of 329 physicians responded to the questionnaire, which is a rather good sample. However an accurate calculation of the response rate was not possible. Even though it is known how many physicians are members of the Portuguese Medical Association, it was not possible to know how many of them actually received the online invitation to participate in the study. The percentage of physicians in our sample with 35 years or younger is $44.4 \%$, which is lower than what is known for the population registered with the PMA [39]. Also, the use of an online approach could represent a bias towards younger physicians who are most prone to use the e-mail on a regular basis.

A reminder was sent 1 month after the initial e-mail message to increase the response rate. To ensure questionnaire anonymity, the reminder was sent to the complete list of physicians, requesting those that had participated in the first round to skip the invitation. However, the possibility of duplicate responses cannot be excluded with certainty.

It should be noted that this questionnaire was intended for all medical specialists. However, family physicians were the most represented specialists in the study. This may indicate that family physicians are more aware of the relevance of BZD utilization and consumption, since they are responsible for most BZD prescription refills.

Further studies to clarify the possible association between physicians and patients believes and attitudes towards BZD and the chronic use of these drugs are warranted.

\section{Conclusion}

Our study showed that, in Portugal, physicians are aware of the risks of BZD chronic use. Family physicians seem to have significantly less positive beliefs and attitudes towards BZD's prescription when compared with other specialists. They also have a better self-perception of literacy about BZD, although expressing concerns about their skills to help patients with BZD withdrawal. The results of this study represent a significant contribution to a better understanding of physicians' beliefs and attitudes associated with prescription and continued use of BZD in Portugal. These results should be taken in consideration when addressing future medical educational interventions, especially aimed at capacitating physicians to motivate and help patients to cease BZD consumption.

\section{Abbreviations}

BZD: Benzodiazepines; DHD: Defined daily dose per 1000 persons;

KMO: Kaiser-Meyer-Olkin; OECD: Organization for Economic Co-operation and Development; PMA: Portuguese Medical Association; PUBS: Perception about Use of BZD Scale

Acknowledgements

The authors would like to thank the Portuguese Medical Association for their support to this study. The authors would also like to acknowledge all participating physicians for taking the time to complete the survey. 


\section{Funding}

Calouste Gulbenkian Foundation funded this study. The funder had no role in the study design, data collection, data analysis, interpretation of data, presentation of results, or decision to submit for publication.

\section{Availability of data and materials}

The data that support the findings of this study are not publically available (as per the Portuguese Law enforcement), but summary data can be made available upon reasonable request. Interested persons should contact the corresponding author.

\section{Authors' contributions}

IN. was involved in every step of the study (literature review, questionnaire development, data collection, data analysis) and prepared the first draft of the paper. JO. and MF. participated in questionnaire development and manuscript revision. OS. was involved in the questionnaire development, data analysis and manuscript revision. VM. (principal investigator) was responsible for study design and coordination and for manuscript revision. All authors contributed for and agreed with the final version of the paper.

\section{Ethics approval and consent to participate}

The study was approved by the Regional Health Administrations' Ethics Committee and authorized by the Portuguese Data Protection Authority. Informed consent was implied by submission of a completed survey questionnaire.

\section{Consent for publication}

Not applicable.

\section{Competing interests}

The authors declare that they have no competing interests.

\section{Publisher's Note}

Springer Nature remains neutral with regard to jurisdictional claims in published maps and institutional affiliations.

\section{Author details \\ ${ }^{1}$ Instituto de Medicina Preventiva e Saúde Pública, Faculdade de Medicina, Universidade de Lisboa, Av. Prof. Egas Moniz, 1649-028 Lisbon, Portugal. ${ }^{2}$ Administração Regional de Saúde de Lisboa e Vale do Tejo IP, Av. Estados Unidos da América 77, 1700-179 Lisbon, Portugal. ${ }^{3}$ Instituto de Saúde Ambiental, Faculdade de Medicina, Universidade de Lisboa, Av. Prof. Egas Moniz, 1649-028 Lisbon, Portugal.}

\section{Received: 22 December 2018 Accepted: 16 May 2019}

\section{Published online: 25 May 2019}

\section{References}

1. Osswald W, Guimarães S. Drug therapy and its pharmacological bases [Terapêutica medicamentosa e suas bases farmacológicas]. 4th Editio. Porto Editora; 2004. 90-107 p.

2. Ashton H. Benzodiazepines: How they work \& how to withdraw [internet]. 2002 [cited 2015 Oct 8]. Available from: http://www.benzo. org.uk/manual/index.htm

3. Eagles L. Guidance for prescribing and withdrawal of benzodiazepines and hipnotics in general practice [Internet]. 2008. p. 1-16. Available from: http:// www.benzo.org.uk

4. Kollen BJ, van der Veen WJ, Groenhof F, Donker GA, van der Meer K. Discontinuation of reimbursement of benzodiazepines in the Netherlands: does it make a difference? BMC fam Pract [internet]. BMC Fam Pract. 2012; 13(1):111 Available from: http://www.pubmedcentral.nih.gov/articlerender. fcgi?artid=3534512\&tool=pmcentrez\&rendertype=abstract.

5. Maria VA, Pimpão MV, Carvalho ML. Characterization of Benzodiazepine Consumption in Primary Health Care [Caracterização do Consumo de Benzodiazepinas em Cuidados de Saúde Primários]. Rev Port Clínica Geral. 1994;11:99-114

6. Olfson M, King M, Schoenbaum M. Benzodiazepine use in the United States. JAMA Psychiatry [Internet] 2015;72(2):136-142. Available from: https://www. ncbi.nlm.nih.gov/pubmed/25517224.

7. Cunningham CM, Hanley GE, Morgan S. Patterns in the use of benzodiazepines in British Columbia: Examining the impact of increasing research and guideline cautions against long-term use. Health Policy (New York) [Internet]. Elsevier Ireland Ltd; 2010;97(2-3):122-9. Available from: https://doi.org/10.1016/j.healthpol.2010.03.008

8. Carrasco-Garrido P, Hernández-Barrera V, Jiménez-Trujillo I, EstebanHernández J, Álvaro-Meca A, López-De Andrés A, et al. Time trend in psychotropic medication use in Spain: a nationwide population-based study. Int J Environ Res Public Health. 2016;13(12).

9. García MAF, Olry de Labry Lima A, Ferrer Lopez I, Bermúdez-Tamayo C. Analysis of changes in trends in the consumption rates of benzodiazepines and benzodiazepine-related drugs. J Pharm Policy Pract Journal of Pharmaceutical Policy and Practice; 2018;11(1):1-8.

10. Furtado C. Psychopharmaceuticals: Evolution of consumption in Portugal mainland (2000-2012) [Psicofármacos: Evolução do consumo em Portugal Continental (2000 - 2012)]. Infarmed, IP. 2014:1-21.

11. OECD. OECD Health data: pharmaceutical market. 2017.

12. French DD, Campbell R, Spehar A, Angaran DM. Benzodiazepines and injury: a risk adjusted model. Pharmacoepidemiol Drug Saf. 2005;14(1):17-24.

13. Barbone F, McMahon AD, Davey PG, Morris AD, Reid IC, McDevitt DG, et al. Association of road-traffic accidents with benzodiazepine use. Lancet. 1998; 352(9137):1331-6.

14. Airagnes G, Pelissolo A. Lavall??E M, Flament M, Limosin F. benzodiazepine misuse in the elderly: risk factors, consequences, and management. Curr psychiatry rep [internet]. Current Psychiatry Reports. 2016;18(10) Available from: https://doi.org/10.1007/s11920-016-0727-9.

15. Gray SL, Dublin S, Yu O, Walker R, Anderson M, Hubbard RA, et al. Benzodiazepine use and risk of incident dementia or cognitive decline: prospective population based study. BMJ [Internet]. 2016;352(feb02_4):i90 Available from: http://www.bmj.com/content/352/bmj.i90.

16. Shash D, Kurth T, Bertrand M, Dufouil C, Barberger-Gateau P, Berr C, et al. Benzodiazepine, psychotropic medication, and dementia: a populationbased cohort study. Alzheimers Dement. 2016;12(5):604-13.

17. Takada M, Fujimoto M, Hosomi K. Association between benzodiazepine use and dementia: data Mining of Different Medical Databases. Int J Med Sci [Internet]. 2016;13(11):825-834. Available from: http://www.medsci.org/v13p0825.htm

18. Hinrichsen A, Leipzig R. Review : supervised withdrawal plus other interventions reduces benzodiazepine use in older persons. Am Coll Physicians. 2014;161:2-3.

19. Vicens C, Bejarano F, Sempere E, Mateu C, Fiol F, Socias I, et al. Comparative efficacy of two interventions to discontinue long-term benzodiazepine use: cluster randomised controlled trial in primary care. $\mathrm{Br} J$ Psychiatry [Internet]. 2014;204(6):471-479. Available from: https://doi.org/10.1192/bjp.bp.113.134650

20. Anthierens S, Habraken H, Petrovic M, Deveugele M, De Maeseneer J, Christiaens T. First benzodiazepine prescriptions. Qualitative study of patients' perspectives. Can Fam Physician. 2007;53:1200-1.

21. Anthierens S, Habraken H, Petrovic M, Christiaens T. The lesser evil? Initiating a benzodiazepine prescription in general practice. Scand J Prim Health Care [Internet]. 2007;25(4):214-219. Available from: https://doi.org/10.1080/ 02813430701726335

22. Cook JM, Marshall R, Masci C, Coyne JC. Physicians' perspectives on prescribing benzodiazepines for older adults: a qualitative study. J Gen Intern Med. 2007;22(3):303-7.

23. Siriwardena AN, Qureshi Z, Gibson S, Collier S, Latham M. GPs' attitudes to benzodiazepine and "Z-drug" prescribing: a barrier to implementation of evidence and guidance on hypnotics. Br J Gen Pract. 2006;56(533):964-7.

24. Anthierens S, Pasteels I, Habraken H, Steinberg P, Declercq T, Christiaens T. Barriers to nonpharmacologic treatments for stress, anxiety, and insomnia. Family physicians' attitudes toward benzodiazepine prescribing. Can Fam Physician. 2010;56:398-406.

25. Cottraux J. Nonpharmacological treatments for anxiety disorders. Dialogues Clin Neurosci. 2002;4(3):305-19.

26. Vyas KU. Non-pharmacological management of insomnia. Br J Med Pract. 2013;6(3):6-10.

27. Maria VA. Benzodiazepine chronic use: the responsibility of the family physician.[Consumo Crónico de Benzodiazepinas: a responsabilidade do Médico de Família.]. Rev Port Clínica Geral. 1994:11:91-2.

28. Janeiro MS. Benzodiazepine prescription in a primary health care unit of the Baixo Alentejo region [Prescrição de benzodiazepinas numa extensão rural do Baixo Alentejo]. Rev Port Clínica Geral. 2000;16:361-77.

29. Sirdifield C, Anthierens S, Creupelandt H, Chipchase SY, Christiaens T, Siriwardena AN. General practitioners' experiences and perceptions of 
benzodiazepine prescribing: systematic review and meta-synthesis. BMC Fam Pract. 2013;14(191):2-13.

30. Bartlett MS. A note on the multiplying factors for various chi square approximations. J R Stat Soc. 1954;16(Series B):296-8.

31. Tavakol M, Dennick R. Making sense of Cronbach 's alpha. Int J Med Educ. 2011;2:53-5.

32. Siriwardena AN, Apekey T, Tilling M, Dyas JV, Middleton H, Ørner R. General practitioners' preferences for managing insomnia and opportunities for reducing hypnotic prescribing. J Eval Clin Pract. 2010;16(4):731-7.

33. Srisurapanont M, Garner P, Critchley J, Wongpakaran N. Benzodiazepine prescribing behaviour and attitudes: a survey among general practitioners practicing in northern Thailand. BMC Fam Pract. 2005;6:1-5.

34. Ajzen I, Joyce N, Sheikh S, Cote NG. Knowledge and the prediction of behavior: the role of information accuracy in the theory of planned behavior. Basic Appl Soc Psych. 2011;33(2):101-17.

35. Furtado C, Teixeira I. Use of Benzodiazepines in Portugal mainland (19992003) [Utilização De Benzodiazepinas Em Portugal Continental (1999-2003)]. Acta Medica Port. 2006;19:239-46.

36. Almeida I miguel C. de. Portuguese National Mental Health Plan ( 2007 2016 ) executive summary. Ment Heal Fam Med. 2009;6:233-44.

37. Miller W, Rollnick S. Motivational interviewing: helping people change. 2nd ed. New York: The Guilford Press; 2002.

38. Loscertales HR, Wentzky V, Dursteler K, Strasser J, Hersberger KE, Arnet I, Successful withdrawal from high-dose benzodiazepine in a young patient through electronic monitoring of polypharmacy: a case report in an ambulatory setting. Ther Adv Psychopharmacol. 2017;7(5):181-7.

39. Ordem dos Médicos. Ordem dos Médicos - Estatísticas Nacionais [Internet]. 2017 [cited 2019 Apr 2]. Available from: https://ordemdosmedicos.pt/ estatisticas-nacionais/\#1505070622822-9e31b1b1-6d1a.

Ready to submit your research? Choose BMC and benefit from:

- fast, convenient online submission

- thorough peer review by experienced researchers in your field

- rapid publication on acceptance

- support for research data, including large and complex data types

- gold Open Access which fosters wider collaboration and increased citations

- maximum visibility for your research: over $100 \mathrm{M}$ website views per year

At $\mathrm{BMC}$, research is always in progress.

Learn more biomedcentral.com/submissions 